\title{
Advertisement Parody under CBR Model
}

\author{
Zhimin Xiang \\ Sichuan Preschool Educators College \\ Mianyang, Sichuan, China 621709
}

\begin{abstract}
As a linguistic device, parody usually takes advantage of some existing language forms to convey new information. The present study, based on two fundamental theories in cognitive linguistics - relevance theory and conceptual blending theory plus three accompanying key concepts, namely "conceptual blending", "cognitive context" and "relevance" aims at a comprehensive interpretation of advertisement parody.
\end{abstract}

Keywords-advertisement; parody; conceptual blending; cognitive context; relevance

\section{INTRODUCTION}

As we all know, nowadays in the modern commercial society, parody, as one of the most significant rhetorical devices, is almost everywhere in the advertisements of mass media. It finds its way in newspapers, magazines, outdoor billboards, TV commercials and even our everyday speech. Both in Chinese and English advertisements, it is easy for all to perceive that parody is more and more frequently exploited to enhance the attention value of the language, strengthen the communicative effect of the utterance and promote the sale of the product or service in question. And since both fang ni (仿拟) and parody can trace their root well back to ancient times, they has aroused academic interest of many researchers. Up till now, there have been considerable achievements in the study of advertisement parody. A great number of books and articles have already been published in major publishing houses home and abroad. However, as an old member of the big rhetorical family, parody yet does not get the attention it deserves compared with metaphor or metonymy which has recently been quite in the spotlight. Generally speaking, there are three motives for conducting the present research of advertisement parody from the perspective of cognitive linguistics. First, as we have just mentioned above, the intentional use of parody in advertisements is getting more and more ubiquitous in the modern commercial society. Parody is no longer taken for granted as a simple rhetorical means ready to be employed to add luster to our daily communication like puns and satires. Second, another important motive for the present study is that so far, the research field of advertisement parody, although being a vibrant and promising one, has been so messy and divided that it desperately calls for a coordinated, systematic and effective approach. Third, another impetus to conduct this research is that right till now, despite inspiring efforts by some aspiring researchers, the study of advertisement parody has not been systematically touched upon by cognitive linguists in terms of the theoretical framework they have applied. Therefore, comparatively speaking, our present approach is new and promising to study advertisement parody.

In a nutshell, this paper aims at a comprehensive cognitive explanation of advertisement parody in line with a new CBR analytical model, which is proposed through integrating Conceptual Blending Theory and Relevance Theory in cognitive linguistics. The CBR model will be applied to the analysis and discussion of advertisement parody from the perspective of phonetics, semantics, pragmatics and cognitive linguistics; in the hope of exploring the cognitive mechanism underlying advertisement parody.

\section{THEORETICAL BASIS: CBR}

In order to bridge the gaps found in the previous studies of advertisement parody, the present research is to apply two fundamental theories of cognitive linguistics-Conceptual Blending Theory and Relevance Theory to analyze statistically and systematically the advertisement parody in the following two sections. The solution to the gaps consists of two parts: the theoretical framework, and data analysis and discussion. This section mainly establishes the theoretical framework. On the basis of cognitive linguistics, the theoretical basis of CBR is constructed out of Conceptual Blending Theory and Relevance Theory. The former evolves from Mental Space Theory and is now also called Conceptual Integration Theory, Blended Space Theory or simply Blending Theory; for the convenience of this thesis, we choose to adopt the most accepted one right nowConceptual Blending Theory. And the latter can trace its root back to the relevant maxim of the Cooperation Principle- a milestone in pragmatics and human communication. Therefore the initial letters $\mathrm{C}$ and $\mathrm{B}$ in the CBR model represent Conceptual Blending, and the last letter $\mathrm{R}$ stands for Relevance.

\section{A. Feasibility of the Integration}

As we have mentioned before, both CBT and RT are essential components of cognitive linguistics. Now let us take a closer look at the background of the theoretical convergences and cross-fertilization between CBT and RT. First of all, the two fundamental cognitive linguistic theories share identical linguistic philosophical background. Both CBT and RT can trace their root back to cognitivism in linguistic philosophy. Under CBT or RT theoretical framework, no matter what kind of meaning it is, it all needs to be constructed by human beings' mental processing and 
therefore relies to a large extent on their general cognitive abilities and strategies. Second, both CBT and RT stressed the economic principle of linguistic encoding and the role played by conceptual blending in the on-line meaning construction. These two similarities shared by CBT and RT constitute the background of their theoretical convergences.

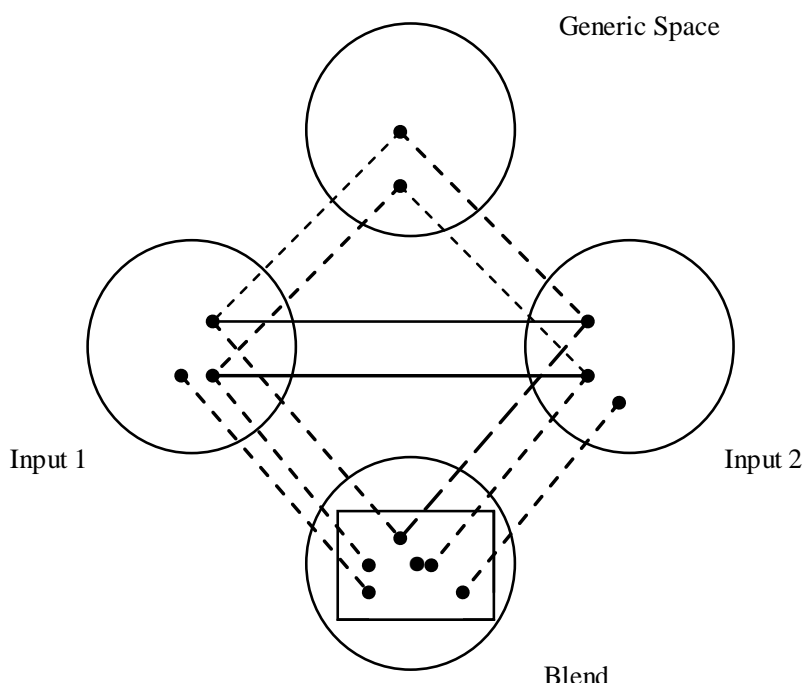

Fig. 1. The network model of conceptual integration. (Fauconnier \& Turner, 2002, p. 46)

The original CBT theoretical framework demonstrates the dynamic meaning construction and exposes mental space mechanism in the process, showing its sound explanatory power to account for on-line, dynamic and fuzzy cognitive activities. And we can't deny that its four-space model really gives us a lot of inspiration to construct the new model. Specifically speaking, we must retain all the merits of the original four-space model of CBT while try to improve it by making some amendments to its demerits.

And what kind of amendments should we make to the original four-space model?

First, we should pay much more attention to the nature of generic space and the crucial role it plays in the network model, and the governing cognitive principle or mechanism concerning its interaction with two input spaces and the final blended space.

Second, we should try to unload the overwhelming responsibility of the blended space in the production of emergent structure and elucidate the largely underspecified nature of the interacting mechanism between blended space and generic space.

Third, according to Fauconnier \& Turner (2002, p. 49), composition, completion and elaboration lead to emergent structure in the blend and the three steps are closely related. However, we think that the first two steps are carried out in the processing space of CBR, and only elaboration is conducted in the blend. In order to show their close interrelationship, the processing space and the

\section{B. Characterization of the New CBR Model}

Simply put, conceptual blending theory mainly contains two components: the working mechanism of blending work within the mental spaces and constitutive and governing principles accompanying it. And the network model of conceptual integration is as follows "Fig. 1":

blend will be represented with two convergent circles in the CBR network. We use a dotted circle to represent the processing space in that it is considered to be hidden but essential to the blending.

Therefore, based on the brief review of both the merits and demerits of the original four-space model above, now we prepare to propose a five-space conceptual integration network which is demonstrated by the following figure "Fig. 2".

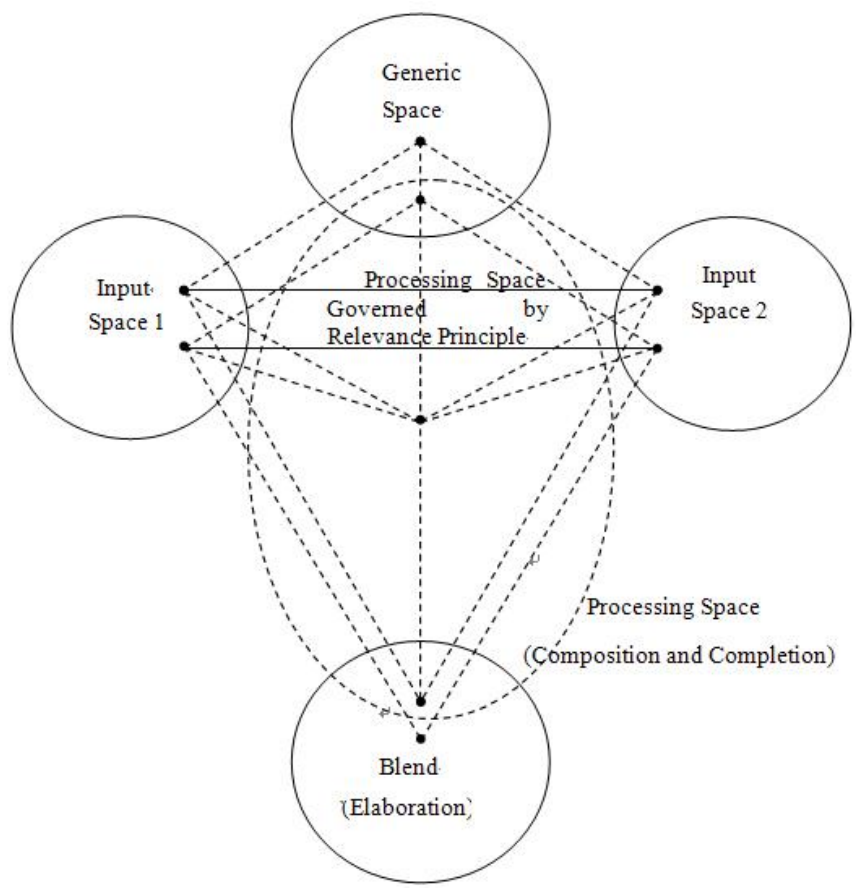

Fig. 2. The network of CBR

\section{DATA DESCRIPTION, ANALYSIS AND DISCUSSION}

\section{A. Phonetic Relevance in Sound-evoked Word Parody}

English is an intonation language. Compared with Chinese which possesses so many nuances in its sound system, the sound variation in English is not so outstanding and therefore to a certain extent, the number of homophones is much smaller than that of Chinese. However, this deficiency is effectively compensated by the fact that English, as a typical synthetical language, has a wealth of phonemes and word affixes. So in our study, we also find a great number of sound-evoked word parodies in English advertisement. For example:

1) My Goodness! My Guinness! 
This is a classical advertisement for the beer - Guinness. In English-speaking countries, "My Goodness" is a popular spoken form to express one's surprise. The word "Guinness", the brand name of the beer, shares the same suffix and sound with the word "goodness", which is provided as an optimal stimulus by the advertiser to make manifest a set of contextual assumptions to the customer. With this ostensive stimulus, the customer can set out to find the intended optimal relevance in his cognitive environment.

2) We know eggsactly how to sell eggs.

And this is an innovative ad for a company whose major business is selling eggs. The word "eggsactly" obviously parodies the word "exactly" through phonetic imitation. A big spotlight of this ad is that in its interpretation, the last word of the ad "eggs" proves to be such a powerful link between the hypotext "exactly" and the temporary nonce word "eggsactly".

\section{B. Semantic Relevance in Meaning-evoked Sentence Parody}

Apart from phonetic relevance, there is another major kind of relevance achieved between the hypotext and the advertised goods - semantic relevance. In meaning-evoked sentence parody, the hypotexts usually take the forms as familiar idioms or old sayings. And one of the biggest merits of employing idioms or old sayings as hypotexts is that both of them have stood the test of time and possess a high cognitive value in terms of an ostensive stimulus.

In English, there are also a lot of meaning-evoked sentence parodies. For example:

1) To smoke or not to smoke, that is a question. (an ad for cigarette)

This ad parodies the well-known line in Hamlet, a famous play written by the great playwright Shakespeare "To be or not to be, that is the question." The original hypotext aims to describe the extreme "survival or suicide" mindset of Hamlet the hero. And the ad maker, drawing his inspiration from the fact that smokers are confronted with the same psychological dilemma when it comes to the issue of smoking or not, accomplishes wonderfully the task of making an optimal ostensive stimulus mutually manifest to him and his counterpart - the target customer. What is humorous is that although smoking or not is also an embarrassing dilemma, it is definitely not the life-or-death issue Hamlet faces in the hypotext. And the humor carried by the ad will most probably prompt a smoker to make a quick decision.

2) A mars a day keeps you work, rest and play. (an ad for Mars chocolate)

This innovative ad is actually created by combining two old sayings in English: "an apple a day keeps the doctor away" and "all work and no play makes Jack a dull boy". Here the advertiser just wants to implicate that the nourishing effect of Mars chocolate is almost the same as that of apples and therefore having a piece of it everyday will make you energetic in work and relaxed in rest and play.
Similar explanations can be made of such meaningevoked English sentence parodies as "Better late than the late", "Not all cars are created equal", etc.

\section{Phonetic and Semantic Relevance in Some Special Cases}

In the previous section during our discussion of phonetic relevance in sound-evoked word parody, we have already pointed out the limited impact of employing phonetic relevance alone in this multi-media world. In fact in our early pilot study of the data, we often find that nowadays as far as advertisement parodies are concerned, single employment of one type of relevance to establish the link between the hypotext and the advertising target sometimes really falls short of the advertiser's ever-rising expectations. Under such circumstances, we do feel that at present there appears to be a paradigm shift in the creation of advertisement parody — from simple employment of phonetic or semantic relevance to the much more complicated application of both phonetic and semantic relevance in just one single piece of ad. In the following are some special cases in which a combination of phonetic and semantic relevance is clearly demonstrated:

\section{1) Thirst come, thirst served. (an ad for Coca Cola)}

The first sight of the ad reminds us of a famous old saying in English "First come, first served" which indicates that in western society, the principle of equality and the spirit of competition are well observed. So why is the hypotext altered in such a way? Why is the word "first" in the hypotext changed into the word "thirst" in the parody text? As is indicated above, this is an ad employed by the Coca Cola Company in 1932, with the aim to appealing to thirsty customers. The alteration from "first" to "thirst" is obviously evoked by the sound of the same consonant clusters "irst", yet the creation of the whole advertisement parody is certainly evoked by the meaning of the original hypotext. The advertisement parody just indicates that whoever the customer is, be him a prince or a pauper, as long as he chooses and drinks Coca Cola, his thirst will be equally quenched.

\section{2) Love at First Flight. (an ad for an air-line)}

When the ad first strikes our eyes, we are shivering with delight about the ingenuity of language conveyed by it. And clearly this ingenuity establishes itself on the close link between the hypotext "Love at first sight" and the advertisement parody "Love at First Flight". By cleverly employing the proper hypotext and adapting it to the local linguistic context, the advertiser did quite an impressive job in providing an optimal ostensive stimulus to the target customers to seek relevance in their cognitive environments. Furthermore at close scrutiny, we get another happy surprise from the ad: the word "flight" in the sentence parody apparently parodies the word "sight" in the hypotext. "Flight" shares the same suffix and similar sound with "sight". In the sentence parody, not only the meaning of the hypotext is well preserved, but also new contextual assumptions are added to it: Just as people fall in love with a charming lover at their first eye contacts, the target customers will just admire the flights provided by the airline 
in the same way. In other words, by choosing the most appropriate hypotext, the new sentence parody successfully inherits the romantic sense of the hypotext and makes one imagine the comfort of taking the airline's flights and maybe the happy possibility of meeting one's other half during the flight. And via the close sound link between "flight" and "sight", the ad leaves a much enduring impression on the target customers.

Another important point to which we want to call the readers' attention is that in the two marvelous parodies above, another significant figure of speech-alliteration can be easily spotted by observant eyes. Specifically speaking, the two "thirsts" in the first instance and "first" and "flight" in the second instance. This fact also consolidates our previous claim: nowadays in this multi-media world, a successful advertisement usually exploits different kinds of rhetorical devices to achieve relevance. Actually in our pilot research, we often find that alliteration is especially favored and thus usually employed by western advertisers to make an advertisement parody and achieve phonetic relevance at the same time.

\section{CONCLUSION}

\section{A. Contribution}

In this paper, we have proposed Conceptual Blending Relevant model (CBR) by integrating two fundamental theories of cognitive linguistics - Conceptual Blending Theory (CBT) and Relevance Theory (RT) and adding a relevance-governed Processing Space to the original fourmodel conceptual integration network of Conceptual Blending Theory (CBT).

\section{B. Limitations and Suggestions}

Firstly, since the data are collected from the internet, CNKI and books dealing with advertisements, they can only be comparatively satisfactory for our present research in terms of the validity and representativeness.

Secondly, the advertisement parody in the corpus is only classified into two types in this thesis - sound-evoked word parody and meaning-evoked sentence parody for the convenience of our present discussion. But in fact, some overlaps do appear in the classification. Furthermore, as we choose only the most salient features as the criterion, the conclusions drawn accordingly can not avoid being a bit subjective.

Thirdly, some data explanations and discussions given in this thesis are based on inferences of advertisers and audiences' psychologies, which is hard to verify and quantify. Some explanations out of our personal understandings may not be satisfactory. So any criticisms and suggestions will be highly appreciated.

We are now living in a world of advertisements and advertisement parody is playing a more and more important role in our daily life. To study it from a cognitive perspective with reference to the latest theory will open up a new road for further exploration into its cognitive mechanism and functions. Researches based on a larger-scale corpus collecting the most up-dated data will be of more significance. We are expecting that more and more comprehensive and profound researches concerning advertisement parody are conducted from cognitive perspective.

\section{REFERENCES}

[1] Bache, C. (2005). Constraining conceptual integration theory: Levels of blending and disintegration. Journal of Pragmatics, 37, 1615-1635.

[2] Brandt, L. \& Brandt, P. A. (2002). Making a sense of a blend. Apparatur, 4, 62-71.

[3] Brandt, P. A. (2005). Mental spaces and cognitive semantics: A critical comment. Journal of Pragmatics, 37, 1578-1594.

[4] Coulson, S. (2001). Semantic leaps: Frame shifting and conceptual blending in meaning construction (PP. 1-15). Cambridge: Cambridge University Press.

[5] Coulson, S. \& Oakley, T. (2000). Blending basics. Cognitive Linguistics, 11, 175-196.

[6] Coulson, S. \& Oakley, T. (2005). Blending and coded meaning: Literal and figurative meaning in cognitive semantics. Journal of Pragmatics, 37, 1510-1536.

[7] Croft, W. \& Cruse, D. A. (2004). Cognitive linguistics. Cambridge: Cambridge University Press.

[8] Dentith, S. (2000). Parody. London: Routledge.

[9] Fauconnier, G. (1985). Mental spaces. Cambridge: MIT Press.

[10] Fauconnier, G. (1994). Mental spaces: Aspects of meaning construction in natural language (pp. 86-100). New York: CUP.

[11] Fauconnier, G. (1997). Mappings in thought and language. New York: Cambridge University Press.

[12] Fauconnier, G. \& Turner, M. (1995). Conceptual integration and formal expression. In M. Johnson (Ed.), Journal of Metaphor and Symbolic Activity, 3, 183-204.

[13] Fauconnier, G. \& Turner, M. (1996). Blending as a central process of grammar. In A. Goldberg (Ed.). Conceptual structure, discourse and language (pp. 113-129). Stanford: Center of the Study of Language and Information (CSLI) Publications.

[14] Fauconnier, G. \& Turner, M. (2002). The way we think: Conceptual blending and the mind's hidden complexities. New York: Basic Books.

[15] Jaszczolt, K. M. (2004). Semantics and pragmatics: Meaning in language and discourse. Beijing: Peking University Press.

[16] Lakoff, G. (1987). Women, fire, and dangerous things: What categories reveal about the mind. Chicago: University of Chicago Press.

[17] Lakoff, G. \& Johnson, M. (1980). Metaphors we live by. Chicago: The University of Chicago Press.

[18] Lakoff, G. \& Johnson, M. (1999). Philosophy in the flesh: The embodied mind and its challenge to western thought. New York: Basic Books.

[19] Langacker, R. W. (1991). Concept, image, and symbol: The cognitive basis of grammar. Berlin: Mounton de Gruyter.

[20] Leech, G. (1983). Principles of pragmatics. London: Longman.

[21] Levinson, S. C. (2001). Pragmatics. Beijing: Foreign Language Teaching and Research Press.

[22] Mey, J. (2001). Pragmatics: An Introduction. Beijing: Foreign Language Teaching and Research Press.

[23] Sperber, D. \& Wilson, D. (2001). Relevance: Communication and cognition. Beijing: Foreign Language Teaching and Research Press.

[24] Ungerer, F. \& Schmid, H. J. (2001). An introduction to cognitive linguistics. Beijing: Foreign Language Teaching and Research Press.

[25] Verschueren, J. (2000). Understanding pragmatics. Beijing: Foreign Language Teaching and Research Press. 